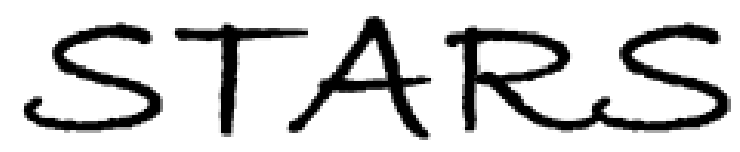

University of Central Florida

STARS

Faculty Scholarship and Creative Works

$10-1-2020$

\title{
Impact of Error Management Culture on Organizational Performance, Management-team Performance and Creativity in the Hospitality Industry
}

Priyanko Guchait

Yu Qin

Juan Madera

Nan Hua

University of Central Florida, nan.hua@ucf.edu

ingyu Wang

Part of the Hospitality Administration and Management Commons, and the Tourism and Travel

Commons

Find similar works at: https://stars.library.ucf.edu/ucfscholar

University of Central Florida Libraries http://library.ucf.edu

This Paper is brought to you for free and open access by STARS. It has been accepted for inclusion in Faculty Scholarship and Creative Works by an authorized administrator of STARS. For more information, please contact STARS@ucf.edu.

\section{Original Citation}

Guchait, P., Qin, Y., Madera, J., Hua, N., \& Wang, X. (2020). Impact of error management culture on organizational performance, management-team performance and creativity in the hospitality industry. International Journal of Hospitality \& Tourism Administration, 21(4), 335-361. https://doi.org/10.1080/ 15256480.2018.1478357

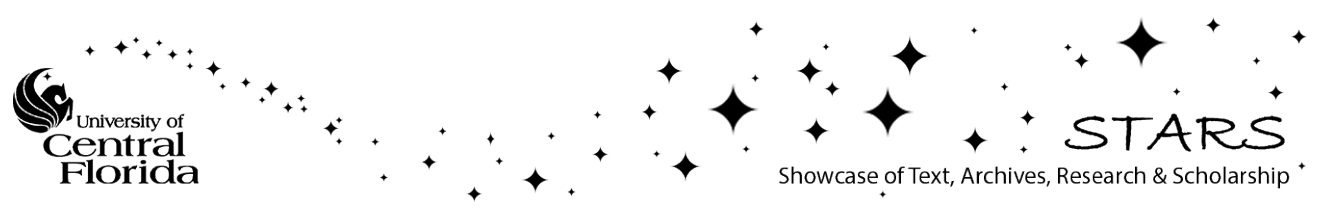


Impact of Error Management Culture on Organizational performance, Management-team Performance and Creativity in the Hospitality Industry

\author{
Priyanko Guchait ${ }^{1}$ \\ Conrad N. Hilton College of Hotel and Restaurant Management \\ 229 C.N. Hilton Hotel \& College \\ University of Houston \\ Houston, Texas, USA \\ Yu Qin \\ School of Hospitality Management \\ Beijing International Studies University \\ Beijing, PRC \\ Juan Madera \\ Conrad N. Hilton College of Hotel and Restaurant Management \\ University of Houston \\ 229 C.N. Hilton Hotel \& College \\ Houston, Texas, USA \\ Nan Hua \\ Rosen College of Hospitality Management \\ University of Central Florida \\ Orlando, FL, USA \\ and \\ Xingyu Wang \\ Conrad N. Hilton College of Hotel and Restaurant Management \\ University of Houston \\ 229 C.N. Hilton Hotel \& College \\ Houston, Texas, USA
}

${ }^{1}$ Corresponding author: pguchait@uh.edu 


\title{
Impact of Error Management Culture on Organizational performance, Management-team Performance and Creativity in the Hospitality Industry
}

\begin{abstract}
The purpose of this study is to examine how organizational error management culture impacts organizational performance, management-team performance and creativity in the hospitality industry. In addition, this study examined the mediating effect of management-team learning behavior between error management culture and outcomes. Data were collected from general managers of 148 hotels in China using survey questionnaires. Results indicated that general managers' perceptions of organizational error management culture had a significant impact on all outcome variables. Additionally, the study found the mediating effect of management-team learning behavior.
\end{abstract}

Keywords: Error management culture, Organizational performance, Creativity, Team performance, Learning behavior, Hospitality 


\section{Introduction}

Errors occur in every organization. Errors often trouble service-oriented industries due to their impact on service experiences and operation processes (Au, Buhalis, \& Law, 2014; Lewis \& McCann, 2004). While errors tend to result in negative outcomes (e.g., loss of revenue, increased cost, loss of clients, customer dissatisfaction), they can lead to positive outcomes as well (e.g., learning, innovation) (Li et al., 2012; Fu \& Mount, 2007; Van Dyck, 2009). In particular, errors may impact profitability depending on the organization's error culture (Dimitrova et al., 2017; Van Dyck et al., 2005). Two dimensions of error culture have been discussed in the literature (Rybowiak et al., 1999). The first and more common dimension of error culture is the 'error prevention culture'-organizations adopting this approach attempt to avoid errors whenever possible (Frese \& Keith, 2015; Reason, 1990). The second and less studied dimension is the 'error management culture' - organizations adopting this approach understand that total elimination of errors is impossible and that errors will occur once in a while (Frese \& Keith, 2015; Reason, 1997). While error prevention aims at the minimization of negative consequences of error occurrence by avoiding errors altogether, the error management approach holds the view that human errors are inevitable and attempts to manage errors proactively and their outcomes (Frese, 1995; Guchait, Kim, \& Namasivayam, 2012). Although it is difficult to predict when and what errors will occur, errors do occur (Van Dyck, 2000).

In hospitality organizations (e.g., hotels, restaurants), errors often happen because of the very nature of the work (high work load, time pressures) (Karatepe, 2012). Errors occur at front of house (checking guests into rooms that are not cleaned, missing reservations, incorrect billing), back of house (housekeepers forget to report items that need repairs), and internal errors involving employees, managers, and department (e.g., incorrect account billings and payments, scheduling 
errors, decision-making errors by managers, errors made in finance or marketing departments) (Guchait, Simons, \& Pasamehmetoglu, 2016b). Errors also occur due to equipment malfunction and through no fault of an individual or organization. It is important that hospitality organizations focus not only on error prevention but also on error management. Therefore, error management is a crucial topic for theory and practice.

Organizations adopting the error management approach focus not only on minimizing the negative consequences of errors by early detection, quick reporting, and error correction, but also on preventing similar errors from occurring in the future by analyzing causes of errors and learning from them (Van Dyck et al., 2013). Although researchers have noticed the importance of error management culture for enhanced organizational performance (Frese \& Keith, 2015), several research gaps are still unfilled in this line of study.

First, there is scarcity of research that has empirically tested the influence of error management culture on organizational outcomes (Guchait, Pasamehmetoglu, \& Madera, 2016a). Scholars have recommended testing the relationship in various contexts to increase the generalizability and validity of findings (Van Dyck et al., 2005) Error management research has been conducted in aviation (Helmreich \& Merritt, 2000), medicine (Edmondson, 2004), and manufacturing (Candranegara, 2015). The current study has contributed to error management literature by examining error management in the error-prone hospitality industry, expanding the scope of this vital error management research area. Specifically, this study examined whether error management culture in hotels can increase hotel performance.

Second, researchers have examined individual perceptions of organizational culture and climate (e.g., Hu, Horng, and Sun (2009) examined employee perceptions of team culture in organizations; Madera, Dawson, and Neal (2013) examined manager perceptions of diversity 
climate in organizations). Previous studies have examined the individual perceptions of error management culture from employees' perspective (Guchait et al., 2016a; Van Dyck et al., 2013). The current study contributed to the error management and service literature by examining the relationship between organizational performance and error management culture perceived by general managers, given that the general managers have a more solid and comprehensive assessment of the organizational culture and performance.

Third, research in almost every discipline, including strategic human resource management, psychology, and hospitality management, is trying to investigate the "black box" linking organizational factors (such as human resource management systems and organizational culture) with organizational outcomes (Becker \& Huselid, 2010). Scholars have recommended filling this research gap by examining the influence of organizational factors (e.g., error management culture) on more proximal outcomes (since firm performance is a distal outcome) (Boselie, P., Brewster, C., \& Paauwe, 2009). Similarly, error management researchers have noted the need to study specific underlying mechanisms in order to gain a thorough understanding of the relationship between error management culture and firm performance (Frese \& Keith, 2015). Recently, error management scholars are making attempts to link error management culture with more proximal outcomes such as firm innovativeness (Frese et al., 2010) and job satisfaction (Jung \& Yoon, 2016). Therefore, to fill the research gap, this study explored two critical outcome variables unstudied before but suggested by researchers in addition to organizational performance: management-team performance and creativity. Investigating these relationships will help clarify the error management process, with findings shedding light on some of the underlying reasons why organizational error management culture impacts firm performance. Additionally, these findings will demonstrate some of the positive outcomes of errors and error management, responding to the 
call for more empirical studies demonstrating the positive consequences of errors (Frese \& Keith, 2015). Moreover, research on teamwork and team performance is limited even though teamwork is predominant in the hospitality industry (Guchait \& Hamilton, 2013). To fill this research gap, the study identified two team-based variables (management-team performance and creativity), both of which are critical for the overall organizational performance (Lewis, 2004), and explored their antecedent: the error management culture. Although not explicitly empirically tested, scholars have implied that error management culture is likely to impact organizational performance via team/group outcomes (Frese \& Keith, 2015). Specifically, they suggested that error management culture is likely to improve group work procedures and creativity, which ultimately would impact organizational performance. Along these lines, recently, Guchait et al. (2016a) linked error management culture with group cohesion (a proximal outcome). Thus, the current study fills another gap in the error management research by incorporating team variables (management-team performance, management-team creativity, and management-team learning behavior).

Fourth, recent research has highlighted the need to test the underlying processes linking error management culture and organizational and employee outcomes (Guchait et al., 2016a; Keith and Frese, 2009). Recently, Guchait et al. (2016a) found that error management culture affected employees' intent to leave through group cohesion and work stress. No studies to date have empirically tested the underlying processes that link organizational error management culture and organizational performance. Thus, there is lack of literature regarding how organizational error management culture influences organizational performance. Previous studies identified learning as a critical component in explaining why error management culture exerts positive outcomes (Frese \& Keith, 2015; Van Dyck et al., 2005). However, this underlying mechanism was never empirically tested. Building on previous research and responding to their call to examine the 
underlying linkages, this study tested the mediating effect of team learning behavior, “characterized by asking questions, seeking feedback, experimenting, reflecting on results, and discussing errors or unexpected outcomes of actions" (Edmondson, 1999, p. 353). Thus, the current study examined the underlying process linking error management culture to organizational performance which has not been tested before, filling an important research gap in the error management and learning literature.

Fifth, studies on error management and error management culture primarily focus on settings other than services, even though services dominate the economic activity of developed countries to $60-70 \%$ of employment and gross domestic product in many economies (Coelho \& Augusto, 2010). Therefore, more studies are needed on error management in services settings given the importance of service errors/failures and service/error recoveries to the success of services firms (Karatepe, 2012). Moreover, recent services scholars are offering broad conceptualizations of service recovery. Effective service recovery is not only about taking actions to resolve the current problem (to satisfy customers) but also about learning from such instances to improve service processes, and providing support to employees (through training and rewards) so that similar problems can be avoided or minimized in the future (Michel et al., 2009; Leticia et al., 2013). The current study provided empirical support for this rationale, which was lacking in previous services research. By examining the proposed relationships in the hotel industry (an example of service industry), this study enlightens practitioners on the need to create error management cultures in hospitality organizations and offers findings with important implications for researchers and practitioners in the hospitality industry.

The purpose of this study is threefold. First, this study examined the direct effect of organizational error management culture on three outcome variables: organizational performance, 
management-team performance, and creativity. Second, this study investigated the mediating effect of management-team learning behavior between error management culture and the outcome variables. Third, this study examined the proposed relationships in a service setting (hotels). In an industry where errors are inevitable, and which often results in negative consequences, it will be interesting to investigate if error management practices in service organizations result in positive organizational outcomes. While the negative effects of errors are more observable and have been of high interest in the past, the current study helps in the development of scientific understanding about the potential positive effects of errors.

\section{Literature review}

\section{Errors and error management culture}

Errors have been defined as "individuals' decisions and behaviors that 1) result in an undesirable gap between and expected and real state and 2) may lead to actual or potential negative consequences for organizational functioning that could have been avoided" (Zhao, 2006, p1013). Some common errors in hotels include missing reservations, incorrect reservations, incorrect billing, dirty rooms, and misplaced items (Lewis \& McCann, 2004). Some common errors in restaurants include delivery of a wrong order, misplaced orders, incorrect charges, and food not cooked as per the order (Dutta et al., 2007). Recently, services scholars have noted the need to investigate errors that can affect firm performance which do not directly involve customers, particularly errors made by managers and employees in various departments such as finance/accounting, revenue management, sales/marketing, and human resources (Guchait et al., 2016b) and include error recoveries that do not directly involve customers. For example, a manager in a restaurant may notice that the wrong food order is about to be delivered or that the food has 
not been cooked properly, and corrects it (quickly stops the delivery and ensures that the food was quickly recooked to perfection) even before the food reaches the customer. Additionally, proactive error recoveries may occur even before a customer complains. For example, a reservation manager in a hotel realizes that the hotel is overbooked and makes alternate reservations for guests in a comparable hotel, even before the guest complains. These types of errors are being examined in hospitality research. The occurrence of various types of errors in the hospitality industry makes the study of error management critical in this industry.

Because of the physiological and psychological limitations of humans, error occurrence is ubiquitous (Hofmann \& Frese, 2011). Therefore, it's important for organization to develop an effective strategy to better cope with avoidable errors. Error management culture refers to organizational practices and procedures related to discussing errors, collecting and communicating error knowledge, assisting in error situations, and identifying and managing errors quickly (Van Dyck et al., 2013). Research has demonstrated that error management culture predicts organizational performance (Dimitrova et al., 2015; Dimitrova et al., 2017). Organizations high in error management culture tend to perform well because they pursue two goals simultaneously. The first goal is controlling, which involves quick error detection and damage control to minimize the negative consequences of errors (Bell \& Kozlowski, 2011). People in these organizations anticipate the likelihood of errors on occasion and focus on containing the potential damage from them (Frese, 1995, Weick et al, 1999). Thus, people working in these cultures have the competency to effectively and efficiently rectify errors. The second goal is learning, which involves preventing similar errors from happening in the future by analyzing their causes, learning from errors, and improving work processes to maximize positive impacts (Hoffman \& Frese, 2011). In high error management cultures, people are encouraged to quickly detect and handle errors, report errors, 
learn from errors, communicate about errors, seek feedback and help from others, use errors as learning opportunities, and increase exploration and experimentation after an error has occurred (Heimbeck et al., 2003; Goodman et al., 2011). On the contrary, working in an organization with low error management culture, employees are more likely to cover up errors, learn less from errors, have negative error cascades, have lowered self-efficacy, and poor performance (Goodman et al., 2011; Dimitrova et al., 2017; Van Dyck et al., 2005). Therefore, error management culture in service organizations is likely to have a positive impact on organizational performance. The following hypothesis is proposed:

Hypothesis 1: Error management culture will be positively related to organizational performance.

The role of management-teams in organizations is crucial for organizational performance in the hospitality industry (Díaz-Fernández et al., 2015; Eesley et al., 2014). The managementteams influence organizational performance through the decisions they make (Souitaris \& Maestro, 2010). Management-teams have both internal and external contacts which help them to manage information effectively (Harmancioglu, 2010). Effective information management, which involves information gathering, processing, and distributing, helps them to make crucial decisions and take actions to increase performance (Collins \& Clark, 2003). The management-team of a hospitality organization (e.g., hotel), which involves the managers of every department, is critical for organizational success since they are responsible for the effective functioning of each department. Moreover, managers are responsible for communication and coordination among various departments. 
Team performance (management-team performance for this study) has been considered crucial for organizational success (Lewis, 2004; Rapp et al., 2014). Services scholars have noted that a successful organization (hotel) requires teamwork (Hu et al., 2009). Although there are few studies on teamwork and team performance in the hospitality industry (such as in the hotel and restaurant industry) (Guchait \& Hamilton, 2013), scholars have noticed the important impact of organizational culture on effective team performance. For example, Hu et al. (2009) showed that a culture of teamwork in hotels influence service innovation performance.

Similarly, error management culture is also likely to improve management-team performance in hospitality organizations. In particular, communication about errors is a critical error management practice (Van Dyck, 2005). Organizations high in error management culture encourage communication about errors that leads to shared knowledge about errors and effective error-management strategies (Cannon \& Edmondson, 2001; Goodman et al., 2011). A study conducted by Edmondson (1996) in a medical setting found that high-performing teams reported more errors. It was suggested that a positive error climate encouraged teams to talk about errors openly, which increased error detection and correction. Moreover, since team members are encouraged to talk freely about errors in such cultures, they develop a mutual understanding of high-risk situations (Frese \& Keith, 2015; Mathieu et al., 2000). In other words, they can anticipate situations with a high likelihood of errors and catch them before negative consequences can unfold (error trapping) (Helmreich \& Merritt, 2000; Hofmann \& Frese, 2011). Such shared knowledge and mutual understanding help members better understand their team environment—members can improve the accuracy of anticipating each other's behaviors and needs and adapt their own behaviors to suit the needs of others in the team/organization (Chou et al., 2008). 
In a study of restaurant-management teams, Guchait (2013) demonstrated that shared knowledge of interpersonal interaction requirements (e.g., role interdependencies) and teammates (e.g., preferences) influences team performance. Moreover, open communication about errors makes it possible for team members to help others in error situations (Guchait et al., 2014b). In a study involving restaurant employees, Guchait et al. (2014b) found that employee perceived that organizational error management culture (which involves communication about service failures and recoveries) increased their helping behaviors in service failure and recovery situations. Finally, open error communication in teams helps with quick error detection-errors undetected or detected slowly tend to have more negative consequences than do errors detected quickly (Reason, 1990; Thomas, 2004) — which leads to efficient handling of errors (Helmreich \& Merritt, 2000; Hofmann \& Frese, 2011). Therefore, error management culture in hospitality organizations is likely to result in effective and coordinated error handling in management-teams, leading to improved management-team performance. The following hypothesis is proposed:

Hypothesis 2: Error management culture will be positively related to management-team performance.

Finally, error management culture is likely to promote management-team creativity in hospitality organizations. Creativity has been defined as members" "generation of novel and useful ideas concerning products, procedures, and processes at work" (Amabile, 1988; Zhou, 2003). Creativity is an important source for organizational innovation and competitive advantage (Kim \& Shin, 2015). Thus, organizations are increasingly seeking to foster individual and team creativity (Cirella et al., 2014; Oldham, 2003). Recently, scholars have noted the value of innovation and creativity in the service industry (Hjalager, 2010; Ottenbacher \& Harrington, 2009; Horng et al., 2013; Dong et al., 2015). Creativity in products and services in hotels and restaurants is more 
essential than ever in order to keep and attract new customers by satisfying their sophisticated demands (Hon \& Lui, 2016; Hu et al., 2009).

Researchers have noted that creativity results not only from the creative potential of individuals but also from team and work contexts (Leung \& Wang, 2015; Hirst et al., 2009). People in high error management cultures are confident that they will not be ridiculed or blamed when errors occur (Nicoletta et al., 2017). Errors are accepted as a natural part of the job, and there is an understanding that errors are likely to occur when people act proactively and creatively (Frese et al., 2010). These people are likely to explore and experiment more often, be creative, and take initiative when they know that they will not be punished for their errors (Robledo et al., 2012; Frese \& Fay, 2001). Therefore, error management culture in hospitality organizations is likely to result in management-team creativity. The following hypothesis is proposed:

Hypothesis 3: Error management culture will be positively related to management-team creativity.

\section{The Mediating Effect of Management-team Learning Behavior}

Learning behavior is a continuous process of reflection and action characterized by activities such as reflecting on results, asking questions, experimenting, seeking feedback, sharing information, asking for help, and discussing errors or unexpected outcomes (Frese \& Keith, 2015; Edmondson, 1999). When team members engage in learning behaviors, they not only acquire knowledge/information on their own (i.e., by learning from their own mistakes), but also learn from others' mistakes (as others share information). Such practices create a pool of knowledge available to team members to improve their own performance and in turn their team's and 
organizational performance in the future. In short, team learning behavior allows for development of shared knowledge and mutual understanding about errors and of effective error handling strategies (Mathieu et al., 2000; Cannon \& Edmondson, 2001). The availability of resources resulting from team learning behavior in organizations is likely to improve work quality, work efficiency, timeliness, and opportunities to accomplish individual and team goals. Therefore, team learning behavior is likely to have an impact on team and organizational performance (Vashdi et al., 2013; Edmondson, 1999). In a study of restaurant-management teams, Guchait and Hamilton (2013) demonstrated that team learning behavior impacts team performance. Scholars have noted the value of team learning behavior in the service industry. Thus, management-team learning behavior is likely to predict management-team performance in service organizations.

Team learning behavior is also likely to result in increased management-team creativity (Boon et al., 2016). A recent study by Hirst et al. (2009) identified the importance of team learning behavior for creativity. Team learning behavior is related to individual learning, which mitigates the psychological risks related to learning and creativity. High team learning behavior informs members that other organizational members are less likely to criticize them for errors and that learning and creativity are fitting, supported, and encouraged (Edmondson \& Lei, 2014; Hirst et al., 2009). Risk reduction is likely to increase creative/innovative behaviors since it signals that: (a) errors are less likely to elicit negative feedback, and (b) teams would encourage each member to try new (creative/innovative) approaches (Hirst et al., 2009). Therefore, management-team learning behavior is likely to predict management-team creativity in hospitality organizations.

Learning has been theorized as the underlying mediating mechanism linking error management culture and organizational performance, but this relationship has not been examined empirically (Boon et al., 2016; Keith \& Frese, 2009). Laurence and Candace (2017) noted that 
mistake tolerance in organizations leads to organizational performance through organizational learning. Since errors are a form of negative feedback, which indicates that things did not go as planned or certain goals have not been achieved, they provide valuable information on how to improve and adapt one's course of action to achieve goals (Homsma et al., 2009). Learning takes place when people are encouraged to learn (Chadwick \& Raver, 2015; Heimbeck et al., 2003). It is easier to say "learn from your errors, mistakes, and failures." However, whether or not organizational members and teams can learn is impacted by the organizational culture towards errors. Leaders and organizations tend to advocate strict adherence to company protocols and consequently focus on avoiding errors, while at the same time expecting timely reports of errors (Leroy et al., 2012). As a result, employees find themselves in a double bind situation, struggling to decide whether to hide or reveal errors. This situation could be especially important in the hospitality industry (e.g., hotels, restaurants). On the one hand, the industry focuses on service quality. It is critical to provide error-free service to guests by introducing sophisticated technologies, developing rigid systems, and enacting strict policies and procedures to control employee behavior (Bekele, 2015; Hart et al., 1990). On the other hand, the industry relies on people reporting failures and errors to improve operating processes, learning from errors, and enhancing error recovery strategies to increase guest satisfaction, all of which tend to dramatically impact company revenue (Tax \& Brown, 1998). Previous studies have indicated that organizations' error management culture can address this issue (Keith \& Frese, 2009; Guchait et al., 2014b).

In a high error management culture, people are encouraged to learn from errors through open error communication (Van Dyck et al., 2005; Van Dyck, 2000). Organizational error management culture promotes a safe learning environment where organizational members feel safe taking interpersonal risks by discussing errors. High error management cultures involve 
interpersonal trust, mutual respect, and a sense of confidence - it is agreed that members will not be embarrassed, rejected, or punished for making errors and speaking up (i.e., communicating about errors, admitting mistakes, seeking feedback) (Hofmann \& Frese, 2011; Edmondson, 1999). Therefore, management-team members are more likely to engage in learning behaviors in high error management cultures. Carmeli and Gittell (2009) found that high-quality relationships conceptualized as shared knowledge, shared goals, and mutual respect result in learning behaviors, which corresponds to the characteristics of the high error management culture.

Finally, although the influence of error management culture and learning behavior has never been linked, previous studies have indicated that organizational culture drives employee attitudes and behaviors (Carmeli, 2005; Vandenberghe, 1999). For example, researchers have shown that organizational culture influences employee turnover, loyalty, satisfaction, commitment, and withdrawal behavior (Gómez-Miranda et al., 2015; Carmeli, 2005; Tepeci, 2005; Sheridan, 1992; Kerr \& Slocum, 1987; Vandenberghe, 1999). Recently, scholars have shown that organizational culture leads to knowledge-sharing (Zheng et al., 2010). Also, recent researchers have demonstrated that a culture/climate of diversity in organizations drives the learning behavior of hotel managers (Guchait et al., 2016c).

Thus, the literature offers sufficient evidence that the presence of an error management culture will result in learning behavior, which in turn, is likely to impact organizational performance, management-team performance, and creativity. Therefore, building on previous research, this study proposes a mediating effect of management-team learning behavior between error management culture and outcome variables. The following hypotheses are proposed:

Hypothesis 4: Management-team learning behavior will partially mediate the relationship between error management culture and hotel performance. 
Hypothesis 5: Management-team learning behavior will partially mediate the relationship

between error management culture and management-team performance.

Hypothesis 6: Management-team learning behavior will partially mediate the relationship

between error management culture and management-team creativity.

\section{Methodology}

Sample and Procedure

Study participants were 148 general managers from hotels in China. The researchers contacted board chairmen of selected hotel corporations and had them contact their human resource departments to solicit GMs' voluntary participation in this study. Hotels with lower star rankings (one-, two-, or three-star hotels) were included for this study. According to the China National Tourism Administration (2010), the number of star-rated hotels in China surged to 14,237 in 2009 from 203 in 1978, with 82.5\% being hotels with lower rankings. Specifically, 41.5\% are three-star hotels; 37.7\% are two-star hotels; and 3.2\% are one-star hotels (China National Tourism Administration, 2010). Given their significant market share in China, this study selected these hotels as the study target sample. The data was collected through human resource departments of selected hotel corporations. GMs were contacted by their human resource departments to answer online the questionnaires prepared for this study.

In collecting information on organizational error management culture, organizational performance, and management-team performance, creativity, and learning behavior, this study focused on general managers for two reasons. First, general managers receive information from all departments and are therefore a more valid source for assessing an organization's culture and performance, and effectiveness of the management-team. The current study was designed from the 
perspective of general managers. Although error management culture impacts both managers and employees, the current research focused on the general managers' assessment of their managementteam. In reality, general managers assess the performance of department managers (e.g., in hotels), while departmental managers assess the performance of their employees in their respective departments. Since, data was collected only from general managers, they were asked to rate the learning behavior, performance, and creativity of the management-team. Second, general managers play a key role in forming and shaping an organization's culture by setting the tone and determining the kinds of behaviors that are expected and supported.

\section{Measures}

Error management culture was measured using the 16-item measure developed by Van Dyck et al. (2005). A sample item from the scale is: "When an error is made, it is corrected right away." The scale reliability for this sample was .91 . Management-team learning behavior was measured with five items from a 7-item learning behavior scale developed by Edmondson (1999). Two items were removed to adjust to the cultural context and facilitate the understanding of respondents. A sample item from the scale is: "The management team regularly takes time to figure out ways to improve its work performance." The scale reliability for this sample was .77 . Organizational performance was measured using two items from a firm performance scale developed by Van Dyck et al. (2005). Organizational goal achievement captures one aspect of organizational performance - namely, how well a firm is doing with regard to its own goals and in comparison to its direct competitors (Van Dyck et al., 2005). General Managers were asked to rate the extent to which their hotel had achieved its most important goal last year; and how successful their hotel was in comparison to their direct competitors (similar operation and size). The scale reliability for this sample was 0.75 . Management-team performance was measured with 
four items from a team performance scale developed by Lewis (2004). A sample item from the scale is: "The management team's deliverables are of excellent quality." The scale reliability for this sample was 0.78. Management-team creativity was measured with four items from an innovative behavior scale developed by Ramamoorthy et al. (2005). Items which were not relevant to the current context of hotels were not used. This decision was made based on interviews with five subject matter experts and four General Managers (this group did not participate in the actual study). The four items included were about creating new ideas for difficult issues, seeking new work methods, mobilizing support (convince others at work) for innovative ideas, and generating original solutions for problems. A sample item from the scale is: "The management team seeks new methods or techniques at work." The scale reliability for this sample was 0.88 . All items were measured on a 5 -point Likert-type scale $(1=$ strongly disagree, $5=$ strongly agree $)$. The survey questionnaire was translated from English to Chinese following the procedures suggested by Brislin (1970). The control variables included age, gender, hotel tenure, and industry tenure.

\section{Results}

\section{Demographics}

Of the 148 general managers from hotels in China, $77 \%$ of the sample was male with an average age of $34.8(\mathrm{SD}=5.2)$, ranging from 27 to 50 . The average tenure of the general manager at their hotel was 3.60 years $(\mathrm{SD}=3.6)$, ranging from 1 to 15 years. Average tenure as the general manager was 2.79 years $(\mathrm{SD}=2.6)$, ranging from 1 to 14 years. With regard to education, $52.2 \%$ had an associate degree, $27.8 \%$ had a bachelor's degree, $3.3 \%$ had a graduate degree, $8.9 \%$ had some college education (no degree), and $7.8 \%$ had a high school degree.

---Insert Table 1 about here--- 


\section{Reliability and Validity Analyses}

A confirmatory factor analysis (CFA) was conducted using AMOS 22 to examine the reliability and validity of the measures. The composite construct reliability (CCR) values were calculated to examine the construct reliability of the measures. As shown in Table 1, the CCR values ranged from .79 to .91 , exceeding the recommended .70 threshold (Fornell \& Larcker, 1981), and thus indicating construct reliability.

Convergent validity was assessed by examining the factor loadings of error management culture, management-team learning behavior, management-team performance, and managementteam creativity. Items with loadings lower than .40 were eliminated, resulting in five items not being used (Hair et al., 2010). All other factor loadings were statistically significant and the standardized loading estimates for the latent variables were higher than .50 (varying from .52 to .94).

As an indicator of convergent validity, the AVE (average variance extracted) scores met the .50 minimum level (ranging from .50 to .67 ), as shown in Table 1 . As a measure of discriminant validity, the AVE values for any two constructs were compared with the square of the correlation estimate between them (Hair et al., 2010). As illustrated in Table 2, all AVE values were greater than the squared correlation estimates demonstrating discriminant validity.

Lastly, the CFA of the measurement model demonstrated adequate fit, $\mathrm{c}^{2}=449.44, \mathrm{df}=287$, $\mathrm{p}<.05 ; \mathrm{CFI}=.90 ; \mathrm{IFI}=.91 ; \mathrm{RMSEA}=.06 ; \mathrm{c}^{2} / \mathrm{df}=1.56$. The goodness-of-fit indices were all satisfactory because CFI and IFI were greater than the .90 threshold, RMSEA was less than the .08 threshold, and the $\mathrm{c}^{2} / \mathrm{df}$ minimum discrepancy was less than the 2 threshold (Byrne, 2001; Steiger, 1990; Tabachnick \& Fidell, 2007). Thus, the results of the CFA further supported the convergent and discriminant validity of the measures. 
---Insert Table 2 about here---

Test of Hypotheses

As shown in Table 2, error management culture was related to organizational performance $(\mathrm{r}=.35, p<.05)$, management-team performance $(\mathrm{r}=.48, p<.05)$ and management-team creativity $(\mathrm{r}=.42, p<.05)$. Multiple regression was used to test Hypotheses $1-3$, entering the control variables in the first step, and error management culture in the second step, with organizational performance, management-team performance, and management-team creativity as the criterion variables. As shown in Table 3, error management culture was significantly related to organizational performance $(\beta=0.33, p<.05)$, thereby supporting Hypothesis 1. Error management culture was positively related to management-team performance $(\beta=0.46, p<.05)$ and management-team creativity $(\beta=0.42, p<.05)$, thereby supporting Hypotheses 2 and 3 .

---Insert Table 3 about here---

Preacher and Hayes' (2008) tests of indirect effects was used to test the mediation models. In this mediation test of indirect effects, the relationship between the predictor variable and the outcome variable are tested with and without the addition of the mediator. The test of the indirect effect examines whether the total effect of the independent variable on the dependent variable is significantly reduced with the addition of the mediator to the model. We used $95 \%$ bias-corrected bootstrapped confidence intervals (CI) to test the significance of the indirect effects because statistical research has suggested that bootstrapping is more appropriate than a normal theory test for studies with smaller sample sizes (see MacKinnon, et al., 2002; Shrout \& Bolger, 2002).

Hypothesis 4 stated that management-team learning behavior would mediate the relationship between error management culture and organizational performance. The results 
showed that the direct paths from error management culture to management-team learning behavior $(\beta=0.73 ; S E=.13 ; t=5.81 ; p<0.01)$ and management-team learning behavior to organizational performance $(\beta=0.44 ; S E=.19 ; t=2.22 ; p<0.05)$ were significant. Additionally, the specific indirect effect from error management culture to organizational performance through management-team learning behavior was significant $(\beta=.31, \mathrm{CI}=.08$ to .60$)$. The results of the Sobel test showed that the reduction (i.e., indirect effect) was significant, $Z=2.09, p<.05$, thereby supporting Hypothesis 4 (see Figure 1).

---Insert Figure 1 about here---

Hypothesis 5 stated that management-team learning behavior would mediate the relationship between error management culture and management-team performance. The results showed that the direct paths from error management culture to management-team learning behavior $(\beta=0.75 ; S E=.09 ; t=7.74 ; p<0.01)$ and management-team learning behavior to management-team performance $(\beta=0.59 ; S E=.08 ; t=7.42 ; p<0.01)$ were significant. Additionally, the specific indirect effect from error management culture to management-team performance through management-team learning behavior was significant $(\beta=.44, \mathrm{CI}=.28$ to .68$)$. The results of the Sobel test showed that the reduction (i.e., indirect effect) was significant, $Z=$ $5.40, p<.01$, thereby supporting Hypothesis 5 (see Figure 2).

\section{---Insert Figure 2 about here---}

Hypothesis 6 stated that management-team learning behavior would mediate the relationship between error management culture and management-team creativity. The results showed that the direct paths from error management culture to management-team learning behavior $(\beta=0.75 ; S E=.09 ; t=7.78 ; p<0.01)$ and management-team learning behavior to management-team creativity $(\beta=0.73 ; S E=.09 ; t=7.64 ; p<0.01)$ were significant. Additionally, 
the specific indirect effect from error management culture to management-team creativity through management-team learning behavior was significant $(\beta=.55, \mathrm{CI}=.28$ to .87$)$. The results of the Sobel test showed that the reduction (i.e., indirect effect) was significant, $Z=5.49, p<.01$, thereby supporting Hypothesis 6 (see Figure 3).

---Insert Figure 3 about here---

\section{Discussion}

Major Findings and Theoretical Implications

The first objective of this study was to investigate how organizational error management culture impacts organizational performance, management-team performance, and creativity. Results indicated that organizational error management culture is critical for organizational success, and it also has a direct significant impact on management-team performance and creativity. These results are consistent with the argument in previous studies (Keith \& Frese, 2009; Van Dyck et al., 2005) that error management culture - which incorporates organizational practices such as sharing error knowledge, communicating about errors, quickly detecting and analyzing errors, effectively enabling error recovery, helping in error situations, and handling errors with coordinated efforts - is directly targeted to avoid and reduce negative error consequences and improve strategies for handling errors in the future. Results are in line with previous studies that noted the importance of rewarding reporting of errors, free-flowing communication, and adopting an interactive learning approach for enhancing organizational success (Edmondson, 1996; Rochlin, 1999; Helmreich \& Merritt, 2000). The findings are consistent with studies in the hospitality industry which found that effective error management practices result in high customer satisfaction and service recovery performance (Guchait et al., 2012; Guchait et al., 2014a). Along with validating the previous research findings (error management culture impacts organizational 
performance), the current study demonstrated two important relationships not examined in previous research. The current study showed that organizational error management culture impacts management-team performance and creativity. These findings make a significant contribution to the error management literature. Scholars have noted the need to study the specific underlying mechanisms to gain a thorough understanding of the relationship between error management culture and firm performance (e.g., Keith \& Frese, 2009). Scholars have suggested that one way to handle this issue is to investigate the impact on more proximal outcomes (since firm performance is a distal outcome). For example, strategic human resource management (SHRM) researchers focus on proximal outcomes of human resource management systems (employee attitudes and behaviors) to understand the link between SHRM and firm performance (Boselie, P., Brewster, C., \& Paauwe, 2009; Huselid \& Becker, 2010; Madera et al., 2017). SHRM research is moving toward more sophisticated ways of linking the HRM-firm performance relationship. The goal is to examine whether HR practices at the organizational level will impact attitudes and behaviors of employees at individual and group levels, which in turn will affect aggregate-level HR outcomes (labor productivity, turnover), which consequently would impact firm performance (financial performance) (Boselie, P., Brewster, C., \& Paauwe, 2009). Along similar lines, the study findings can help explain the relationship between organizational error management culture and firm performance. Research on management-teams has demonstrated the crucial role of management-teams on organizational performance (Collins \& Clark, 2003; Edmondson, 1999). Effectiveness of management-teams in organizations drives organizational performance (Stewart, 2006). Bunderson and Sutcliffe (2003) demonstrated the link between management-team learning orientation on business unit performance. Shared leadership, cohesion, and collective vision of 
management-teams have been linked with firm performance (Ensley et al., 2003). Thus, the current study makes a crucial contribution to error management research.

The second objective of this study was to examine the underlying mechanism that links organizational error management culture with organizational and management-team outcomes. Previous studies had identified learning as the critical component explaining why error management culture results in positive outcomes (Keith \& Frese, 2009; Van Dyck et al., 2005). However, this underlying mechanism was never empirically tested. This study tested this conceptual framework and found that management-team learning behaviors partially mediate the relationship between error management culture and outcomes, with the exception of managementteam performance, which was fully mediated. In addition, this study found that people engage in learning behaviors more often in organizations high in error management culture, which consequently drives organizational performance, management-team performance, and creativity. This is a significant contribution to the error management literature and validates the conceptual framework initially suggested by scholars (e.g., Van Dyck et al., 2005; Keith \& Frese, 2009). In addition, this finding is in line with those from previous studies suggesting that organizational support and context support lead to increased engagement in learning behaviors, which consequently drive team and individual performance (Edmondson, 1999; Guchait et al., 2014a). This finding is also consistent with studies that emphasized how high-quality relationships, as manifested in shared goals, shared knowledge, and mutual respect, lead to increased learning behaviors since people in such organizations feel valued, appreciated, and comfortable saying what they think and feel; these learning behaviors in turn improve organizational processes and work outcomes (Kahn, 2007; Carmeli et al., 2009; Carmeli \& Gittell, 2009). Thus, the current study fills 
a critical gap in the error management research by explaining the underlying mechanism linking error management culture and organizational outcomes.

The third objective was to examine error management culture and proposed relationships in a service setting. Most prior studies on error management have been conducted in non-service settings such as aviation. Recent studies have begun to investigate error management in service settings such as hospitals (Van Dyck et al., 2013). The current study confirmed that error management is crucial to success in the hospitality (hotel) industry. In doing so, this study contributes to the error management literature by increasing its generalizability. The current study also makes a significant contribution to hospitality research. Findings are critical since service scholars have noted that the impact of error management (e.g., recovery strategies) following an error on a company's revenue and profitability can be dramatic and that many companies fail to take advantage of learning opportunities afforded by errors (service errors and failures) (Olaison \& Sørensen, 2014; Tax \& Brown, 1998; Homsma et al., 2009). Recently, scholars have broadly conceptualized service recovery. Researchers have noted that effective service recovery is not only about taking actions to resolve the current problem but also about learning from such instances to improve service processes, and providing support to employees (through training and rewarding) so that similar problems can be avoided or minimized in the future. Further, based on learning, proactive and effective service recovery strategies can be developed in advance so that problems can be quickly detected and resolved in the future (Michel et al., 2009). The current study provides empirical support for this rationale, which was lacking in previous service research. Identifying a new independent variable, scarcely studied in the hospitality literature, this study confirmed that hospitality organizations strong in error management culture drive learning in organizations that impacts organizational outcomes. 


\section{Practical Implications}

This study has important implications for leaders in the hospitality industry. Since human errors are impossible to avoid, leaders should focus on managing errors to reduce their negative impact, learn from errors to avoid making the same mistakes again, and develop better procedures for handling errors effectively in the future. In addition, leaders need to understand that errors can be beneficial—errors are a form of negative feedback that things did not go as planned and as such provide opportunities to learn and innovate. Those service companies that stubbornly stick to a noerror policy will suffer harm in the long run because managers will be afraid to report errors due to concerns about losing their jobs or damaging their self-image. Learning opportunities would be lost since errors, problems, and failures are not being brought forward, analyzed, and resolved. This study found that error management cultures support learning behaviors in organizations that impact team and organizational effectiveness. Thus hospitality organizations should be interested in increased team and organizational performance and in programs that develop a systematic error management approach in order to be cost-effective and gain competitive advantages.

This study has important implications for training in hospitality organizations. Hospitality organizations can implement error management training programs to improve error recovery performance/competency of managers. It is worth noting that several components are critical for error management training. The first component involves training managers to identify errorproducing situations. Such training enables organizational members to identify situations that lead to errors. The second component trains managers how to deal with errors, respond to errors, and understand policies related to correcting errors. The third component involves incorporating simulations, such as role-playing, to provide managers with opportunities for practice, guidance, and immediate feedback. Training should also encourage managers to seek feedback and open 
communication. Lastly, error management training should include both managers and their subordinates so that all members have consistent policies and procedures for managing errors.

Communication is essential in high error management cultures. As such, hospitality organizations need to set up communication channels that are straightforward, confidential, and anonymous. Managers need to be informed and trained on how to report error incidents and organizations need to build a climate of trust and encourage managers to report error incidents without punitive consequences (Helmreich, 2000). At the same time, leaders should be guided on how to document errors. When leaders use proper documentation techniques, managers are more likely to share error information. In addition, documentation of error incidents can be used for training purposes to prevent errors in the future.

Lastly, this study has implications for performance evaluations and awards. First, leaders should emphasize that in lieu of finding employees to blame in error situations, focus should be on resolving the problem and learn from that incident. Behaviors such as quick error detection and correction, helping others in error situations, and preventing errors should be considered during performance evaluations and allocations of awards. Leaders should encourage their subordinates (managers) to share information about errors and seek feedback and help in error situations to resolve the error quickly and effectively. More service organizations should incorporate a constructive orientation toward errors and realize the potential of developing/adopting error management cultures in their organizations.

\section{Limitations and Future Research Directions}

Although this study's findings are valuable for hospitality management, several limitations need to be considered. First, this study found that organizational error management culture exerts a significant influence on organizational and management-team outcomes. As such, although all 
companies may benefit from an error management approach, several other factors unexamined in this study can affect these relationships. Contextual factors such as training and leadership can affect the proposed relationships. Even though error management culture has been shown to lead to organizational and management-team effectiveness, future scholars need to investigate these contextual factors in detail—that is, under what conditions might the error management approach be most effective and under what conditions might it not be?

Second, this study employs a cross-sectional survey design, limiting its causality interpretations. Future research can look at longitudinal data when available and better demonstrate causality by measuring the variables at different time points. Fourth, the current study collected data from one source (hotel general managers). Future research can use a stronger research design and collect data from multiple sources. For example, employees could be asked to rate their perceptions of organizational error management culture, while managers may be asked to rate a hotel's performance.

Third, four items from the error management culture scale and one item from the learning behavior scale had to be removed because of low factor loadings. We believe there could be two reasons. The first issue could be cultural since some items may not fit a specific cultural context. For example, He, Lai, and Lu (2011), collected data from Chinese employees using translated item and deleted some items which were obscure and could not be understood by the Chinese respondents. The second issue could be the issue of translation. Although we followed the translation procedure suggested by Brislin (1970), it is possible that some respondents could not associate with the translated item. Although, it is common to drop items with loadings lower than .40 (e.g., Huang \& Cai, 2015; Zopiatis, Constanti, \& Theocharous, 2014), future research should 
consider doing qualitative studies by conducting in-depth focus group interviews to identify some of these issues before conducting empirical studies.

Finally, confidential financial information (e.g., sales, profitability) was not made available by the hotels for the current study. Therefore, following previous research, the current study used "firm goal attainment" as a criteria of hotel performance (Van Dyck et al., 2005). However, future research can link employees' and managers' perceptions of organizational error management culture to actual firm performance. 


\section{References}

Amabile, T. M. (1988). A model of creativity and innovation in organizations. In B. M. Staw, and L. L. Cummings (Eds.), Research in Organizational Behavior (pp. 123-167). Greenwich, CT: JAI Press.

Amabile, T. M. (1996), Creativity in Context. Boulder, CO: Westview.

Amalberti, R. (1996), La conduite de systèmes à risques, Presses Universitaires de France, Paris.

Argote, L., Gruenfeld, D., \& Naquin, C. (2001). Group learning in organizations. In M. E. Turner (Eds.), Groups at work: Advances in theory and research (pp. 369-411). Mahway, NJ: Lawrence Erlbaum Associates.

Au, N., Buhalis, D., \& Law, R. (2014). Online complaining behavior in mainland China hotels: The perception of Chinese and Non-Chinese customers. International Journal of Hospitality \& Tourism Administration, 15, 248-274.

Becker, B. E., \& Huselid, M. A. (2010). SHRM and job design: Narrowing the divide. Journal of organizational Behavior, 31(2-3), 379-388.

Bekele, S. (2015). Perceived Service Quality and Its Relationship with Customer Loyalty in Ethiopian Hotel Industry. Journal of Contemporary Research in Management, 10, 31-42.

Bell, B. S., \& Kozlowski, S. W. (2011). Collective failure: The emergence, consequences, and management of errors in teams. Errors in organizations, 113-141.

Boon, A., Vangrieken, K., \& Dochy, F. (2016). Team creativity versus team learning: transcending conceptual boundaries to inspire future framework building. Human Resource Development International, 19, 67-90.

Boselie, P., Brewster, C., \& Paauwe, J. (2009). In search of balance-managing the dualities of HRM: an overview of the issues. Personnel Review, 38(5), 461-471.

Brislin, R. W. (1970). Back-translation for cross-cultural research. Journal of cross-cultural psychology, 1, 185-216.

Brown, S.W., Cowles, D.L., \& Tuten, T.L. (1996). Service recovery: its value and limitations as a retail strategy. International Journal of Service Industry Management, 7, 32-45.

Byrne, B. M. (2001). Structural equation modeling with AMOS: Basic concepts, applications, and programming. Mahwah, NJ: Lawrence Erlbaum Associates.

Candranegara, G. (2015). Conflict and error management: A case in the furniture industry. 
Cannon, M.D., \& Edmondson, A.C. (2001). Confronting failure: Antecedents and consequences of shared beliefs about failure in organizational work groups. Journal of Organizational Behavior, 22, 161-177.

Carmeli, A., Brueller, D., \& Dutton, J. E. (2009). Learning behaviours in the workplace: The role of high-quality interpersonal relationships and psychological safety. Systems Research and Behavioral Science, 26, 81-98.

Carmeli, A., \& Gittell, J. H. (2009). High-quality relationships, psychological safety, and learning from failures in work organizations. Journal of Organizational Behavior, 30, 709-729.

Chadwick, I. C., \& Raver, J. L. (2015). Motivating organizations to learn: Goal orientation and its influence on organizational learning. Journal of Management, 41, 957-986.

Chan, C.C.A., Pearson, C., \& Entrekin, L. (2003). Examining the effects of internal and external team learning on team performance. Team Performance Management, 9, 174-181.

China National Tourism Administration (2010). The yearbook of China tourism statistics. Beijing: China Tourism Publishing House.

Chou, L., Wang, A., Wang, T., Huang, M., \& Cheng, B. (2008). Shared work values and team member effectiveness: The mediation of trustfulness and trustworthiness. Human Relations, $61,1713-1742$.

Cirella, S., Radaelli, G., \& B.(Rami) Shani, A. (2014). Team creativity: A complex adaptive perspective. Management Research Review, 37, 590-614.

Collins, C. J., \& Clark, K. D. (2003). Strategic human resource practices, top management team social networks, and firm performance: The role of human resource practices in creating organizational competitive advantage. Academy of management Journal, 46(6), 740-751.

Díaz-Fernández, M. C., González-Rodríguez, M. R., \& Simonetti, B. (2015). Top management team's intellectual capital and firm performance. European Management Journal, 33, 322331.

Dimitrova, N. G., Dyck, C., Hooft, E. A., \& Groenewegen, P. (2015). Don't Fuss, Focus: The Mediating Effect of On-Task Thoughts on the Relationship between Error Approach Instructions and Task Performance. Applied Psychology, 64(3), 599-624.

Dimitrova, N. G., Van Hooft, E. A., Van Dyck, C., \& Groenewegen, P. (2017). Behind the wheel: What drives the effects of error handling?. The Journal of social psychology, 1-15.

Dong, Y., Liao, H., Chuang, A., Zhou, J., \& Campbell, E. M. (2015). Fostering employee service creativity: Joint effects of customer empowering behaviors and supervisory empowering leadership. Journal of Applied Psychology, 100, 1364. 
Dormann, T., \& Frese, M. (1994). Error training: replication and the function of exploratory behavior. International Journal of Human-Computer Interaction, 6, 365-372.

Dutta, K., Venkatesh, U., \& Parsa, H. G. (2007). Service failure and recovery strategies in the restaurant sector: An Indo-US comparative study. International Journal of Contemporary Hospitality Management, 19(5), 351-363.

Edmondson, A. C. (2004). Learning from mistakes is easier said than done: Group and organizational influences on the detection and correction of human error. The Journal of Applied Behavioral Science, 40(1), 66-90.

Edmondson, A. (1999). Psychological safety and learning behavior in work teams. Administrative Science Quarterly, 44, 350-383.

Edmondson, A. C., \& Lei, Z. (2014). Psychological safety: The history, renaissance, and future of an interpersonal construct. Annual Review of Organizational Psychology and Organizational Behavior, 1, 23-43.

Eesley, C. E., Hsu, D. H., \& Roberts, E. B. (2014). The contingent effects of top management teams on venture performance: Aligning founding team composition with innovation strategy and commercialization environment. Strategic Management Journal, 35, 17981817.

Fornell, C., \& Larcker, D. F. (1981). Evaluating structural equation models with unobservable variables and measurement error. Journal of Marketing Research, 18, 39-50.

Frese, M. (1991). Error management or error prevention: Two strategies to deal with errors in software design. In H. J. Bullinger (Eds.), Human Aspects in Computing: Design and Use of Interactive Systems and Work with Terminals (pp 776-782). Amsterdam: Elsevier.

Frese, M. (1995). Error management in training: Conceptual and empirical results. In C. Zucchermaglio, S. Bagnara, \& S. Stucky (Eds.), Organizational Learning and Technological Change (pp 112-124). Berlin, Germany: Springer-Verlag.

Frese, M., \& Fay, D. (2001). Personal initiative (PI): A concept for work in the 21st century. Research in Organizational Behavior, 23, 133-188.

Frese, M., \& Keith, N. (2015). Action errors, error management, and learning in organizations. Annual Review of Psychology, 23, 133-188.

Fu, Y., \& Mount, D. (2007). Hotel guests' cumulative satisfaction updating process in the context of service failure and service recovery. International Journal of Hospitality \& Tourism Administration, 8, 77-98.

Goodman, P. S., Ramanujam, R., Carroll, J. S., Edmondson, A. C., Hofmann, D. A., \& Sutcliffe, K. M. (2011). Organizational errors: Directions for future research. Research in Organizational Behavior, 31, 151-176. 
Guchait, P., \& Hamilton, K. (2013). The temporal priority of team learning behaviors vs. shared mental models in service management teams. International Journal of Hospitality Management, 33, 19-28.

Guchait, P., Kim, M.G., \& Namasivayam, K. (2012). Error management at different organizational levels - frontline, manager, and company. International Journal of Hospitality Management, 31, 12-22.

Guchait, P., Madera, J., \& Dawson, M. (2016c). Learning in the service environment: the influence of diversity climate. Journal of Service Theory and Practice, 26, 448-470.

Guchait, P., Pasamehmetoglu, A., \& Madera, J. (2016a). Error management culture: impact on cohesion, stress, and turnover intentions. The Service Industries Journal, 36, in press.

Guchait, P., Pasamehmetoglu, A., \& Dawson, M. (2014a). Perceived supervisor and co-worker support for error management: impact on perceived psychological safety and service recovery performance. International Journal of Hospitality Management, 41, 28-37.

Guchait, P., Pasamehmetoglu, A., \& Abbott, J. L. (2014b). The importance of error management culture in organizations: the impact on employee helping behaviors during service failures and recoveries in restaurants. Journal of Human Resources in Hospitality and Tourism, 14, 45-67.

Guchait, P., Simons, T., \& Pasamehmetoglu, A. (2016b). Error recovery performance: The impact of leader behavioral integrity and job satisfaction. Cornell Hospitality Quarterly, 57, 150161.

Hair, J.F., Black, W.C., Babin, B.J., \& Anderson, R.E. (2010). Multivariate Data Analysis: A Global Perspective. New York, NY: Pearson.

Harmancioglu, N., Grinstein, A., \& Goldman, A. (2010). Innovation and performance outcomes of market information collection efforts: The role of top management team involvement. International Journal of Research in Marketing, 27, 33-43.

Hart, C., Heskett, J. L., \& Sasser, W. E. (1990). The profitable art of service recovery. Harvard Business Review, 68, 148-156.

He, Y., Lai, K. K., \& Lu, Y. (2011). Linking organizational support to employee commitment: evidence from hotel industry of China. The International Journal of Human Resource Management, 22(01), 197-217.

Heimbeck, D., Frese, M., Sonnentag, S., \& Keith, N. (2003). Integrating errors into the training process: The function of error management instructions and the role of goal orientation. Personnel Psychology, 56, 333-362. 
Helmreich, R. L. (2000). On error management: lessons from aviation. British Medical Journal, $320,781-785$.

Helmreich, R. L., \& Merritt, A. C. (2000). Safety and error management: The role of crew resource management. In B. J. Hayward, \& A. R. Lowe (Eds.), Aviation Resource Management (pp 107-119). Aldershot, England: Ashgate Publishing.

Hirst, G., Knippenberg, D. V., \& Zhou, J. (2009). A cross-level perspective on employee creativity: Goal orientation, team learning behavior, and individual creativity. Academy of Management Journal, 52, 280-293.

Hoegl, M., \& Parboteeah, K. P. (2007). Creativity in innovative projects: How teamwork matters. Journal of Engineering and Technology Management, 24, 148-166.

Hofmann, D. A. and Frese, M. (2011), Errors in organizations, Routledge, New York, NY.

Hon, A. H., Hon, A. H., Lui, S. S., \& Lui, S. S. (2016). Employee creativity and innovation in organizations: Review, integration, and future directions for hospitality research. International Journal of Contemporary Hospitality Management, 28, 862-885.

Hu, M. M., Horng, J., \& Sun, Y. (2009). Hospitality teams: Knowledge sharing and service innovation performance. Tourism Management, 30, 41-50.

Huang, Z. J., \& Cai, L. A. (2015). Modeling consumer-based brand equity for multinational hotel brands-When hosts become guests. Tourism Management, 46, 431-443.

Jung, H. S., \& Yoon, H. H. (2016). Error management culture and turnover intent among food and beverage employees in deluxe hotels: the mediating effect of job satisfaction. Service Business, 1-18.

Karatepe, O. M. (2012). Job resources, work engagement, and hotel employee outcomes: a timelagged analysis. Economic Research-Ekonomska Istraživanja, 25(3), 644-665.

Kim, M., \& Shin, Y. (2015). Collective efficacy as a mediator between cooperative group norms and group positive affect and team creativity. Asia Pacific Journal of Management, 32, 693-716.

Kozlowski, S. W. J., \& Ilgen, D. R. (2006). Enhancing the effectiveness of work groups and teams. Psychological Science, 7, 77-124.

Leroy, H., Dierynck, B., Anseel, F., Simons, T., Halbesleben, J. R. B., McCaughey, D., Savage, G. T., \& Sels, L. (2012). Behavioral integrity for safety, priority of safety, psychological safety, and patient safety: A team-level study. Journal of Applied Psychology, 97, 12731281.

Leticia Santos-Vijande, M., María Díaz-Martín, A., Suárez-Álvarez, L., \& Belén del Río-Lanza, A. (2013). An integrated service recovery system (ISRS) Influence on knowledge-intensive business services performance. European Journal of Marketing, 47, 934-963. 
Leung, K., \& Wang, J. (2015). Social processes and team creativity in multicultural teams: A socio-technical framework. Journal of Organizational Behavior, 36, 1008-1025.

Lewis, B. R., \& McCann, P. (2004). Service failure and recovery: evidence from the hotel industry. International Journal of Contemporary Hospitality Management, 6, 6-17.

Lewis, K. (2004). Knowledge and performance in knowledge-worker teams: A longitudinal study of transactive memory systems. Management Science, 50, 1519-1533.

Li, Y. J., Johnson, K. A., Cohen, A. B., Williams, M. J., Knowles, E. D., \& Chen, Z. (2012). Fundamental(ist) attribution error: Protestants are dispositionally focused. Journal of Personality And Social Psychology, 102, 281-290.

Madera, J.M., Dawson, M., \& Neal, J.A. (2013). Hotel managers' perceived diversity climate and job satisfaction: The mediating effects of role ambiguity and conflict. International Journal of Hospitality Management, 35, 28-34.

Madera, J.M., Dawson, M., Guchait, P., \& Belarmino, A.M. (2017). Strategic human resources management research in hospitality and tourism: A review of current literature and suggestion for the future. International Journal of Contemporary Hospitality Management, 29, 48-67.

Mahler, J. G. (2009), Organizational Learning at NASA: the Challenger and Columbia Accidents, Georgetown University Press, Washington D.C.

Mathieu, J. E., Goodwin, G. F., Heffner, T. S., Salas, E., \& Cannon-Bowers, J. A. (2000). The influence of shared mental models on team process and performance. Journal of Applied Psychology, 85, 273- 283.

Michel, S., Bowen, D., \& Johnston, R. (2009). Why service recovery fails: Tensions among customer, employee and process perspectives. Journal of Service Management, 20, 253273.

Nembhard, I.M., \& Edmondson, A.C. (2006). Making it safe: The effects of leader inclusiveness and professional status on psychological safety and improvement efforts in healthcare teams. Journal of Organizational Behavior, 27, 941-966.

Olaison, L., \& Sørensen, B. M. (2014). The abject of entrepreneurship: failure, fiasco, fraud. International Journal of Entrepreneurial Behaviour \& Research, 20, 193 - 211.

Oldham, G. R. (2003). Stimulating and supporting creativity in organizations. In S. E. Jackson, M. A. Hitt, \& A. S. DeNisi (Eds.), Managing Knowledge for Sustained Competitive Advantage (pp 243-273). San Francisco: Jossey-Bass. 
Preacher, K. J., \& Hayes, A. F. (2008). Asymptotic and resampling strategies for assessing and comparing indirect effects in multiple mediator models. Behavior Research Methods, 40, 879-891.

Ramamoorthy, N., Flood, P. C., Slattery, T., \& Sardessai, R. (2005). Determinants of innovative work behavior: Development and test of an integrated model. Creativity and Innovation Management, 14, 142-150.

Rapp, T. L., Bachrach, D. G., Rapp, A. A., \& Mullins, R. (2014). The role of team goal monitoring in the curvilinear relationship between team efficacy and team performance. Journal of Applied Psychology, 99, 976-987.

Reason, J. (1990). Human Error. Cambridge, England: Cambridge University Press.

Reason, J. (1997). Managing the Risks of Organizational Accidents. Hampshire, England: Ashgate Publishing.

Robledo, I. C., Hester, K. S., Peterson, D. R., Barrett, J. D., Day, E. A., Hougen, D. P., \& Mumford, M. D. (2012). Errors and understanding: The effects of error-management training on creative problem-solving. Creativity Research Journal, 24, 220-234.

Rochlin, G. I. (1999). Safe operation as a social construct. Ergonomics, 42, 1549-1560.

Rybowiak, V., Garst, H., Frese, M., \& Batinic, B. (1999). Error orientation questionnaire (EOQ): reliability, validity, and different language equivalence. Journal of Organizational Behavior, 20, 527-547.

Shrout, P. E., \& Bolger, N. (2002). Mediation in experimental and nonexperimental studies: new procedures and recommendations. Psychological Methods, 7, 422-445.

Sitkin, S. B., Sutcliffe, K. M., Roger, G., \& Schroeder, R. G. (1994). Distinguishing control from learning in total quality management: A contingency perspective. Academy of Management Review, 19, 537-564.

Steiger, J. H. (1990). Structural model evaluation and modification: An interval estimation approach. Multivariate Behavioral Research, 25, 173-180.

Tabachnick, B. G., \& Fidell, L. S. (2007). Using Multivariate Statistics (5 ${ }^{\text {th }}$ ed.), New York: Allyn and Bacon.

Tax, S. S., \& Brown, S. W. (1998). Recovering and learning from service failure. Sloan Management Review, 40, 75-88.

Tax, S. S., Brown, S. W., \& Chandrashekaran, M. (1998). Customer evaluations of service complaint experiences: Implications for relationship marketing. Journal of Marketing, 62, 60-76. 
Thomas, M. J. (2004). Predictors of threat and error management: Identification of core nontechnical skills and implications for training systems design. The International Journal of Aviation Psychology, 14, 207-231.

Van Dyck, C. (2000). Putting errors to good use: error management culture in organizations, Thesis, University of Amsterdam. Retrieved from http://dare.uva.nl/document/2/47337

Van Dyck, C. (2009). The tragic 1996 everest expedition: a tale of error culture. Netherlands Journal of Psychology, 65, 22-34.

Van Dyck, C., Frese, M., Baer, M., \& Sonnentag, S. (2005). Organizational error management culture and its impact on performance: A two-study replication. Journal of Applied Psychology, 90, 1228-1240.

Van Dyck, C., Dimitrova, N. G., De Korne, D. F., \& Hiddema, F. (2013). Walk the talk: Leaders' enacted priority of safety, incident reporting, and error management. Advances in Health Care Management, 14, 95-117.

Vashdi, D. R., Bamberger, P. A., \& Erez, M. (2013). Can surgical teams ever learn? The role of coordination, complexity, and transitivity in action team learning. Academy of Management Journal, 56, 945-971.

Weick, K. E., Sutcliffe, K. M., \& Obstfeld, D. (2008). Organizing for high reliability: Processes of collective mindfulness. Crisis management, 3, 81-123.

Wiener, E., Kanki, B., Helmreich, R., Helmreich, R. L., \& Foushee, H. C. (1993). Why crew resource management? Empirical and theoretical bases of human factors training in aviation. In E. Wiener, B. Kanki, \& R. Helmreich (Eds.), Cockpit Resource Management (pp 3-45), San Diego: Academic Press.

Zapf, D., Brodbeck, F. C., Frese, M., Peters, H., \& Prümper, J. (1992). Errors in working with computers: A first validation of a taxonomy for observed errors in a field setting. International Journal of Human-Computer Interaction, 4, 311-339.

Zhao, B., \& Olivera, F. (2006). Error reporting in organizations. Academy of Management Review, 31, 1012-1030.

Zhou, J. (2003). When the presence of creative coworkers is related to creativity: Role of supervisor close monitoring, developmental feedback, and creative personality. Journal of Applied Psychology, 88, 413-422.

Zopiatis, A., Constanti, P., \& Theocharous, A. L. (2014). Job involvement, commitment, satisfaction and turnover: Evidence from hotel employees in Cyprus. Tourism Management, 41, 129-140. 